\title{
$O$ retorno dos ancestrais: Bon Odori e ritos mortuários no Templo Budista Honpa Honganji em Londrina
}

\author{
The return of ancestors: Bon Odori and mortuary rituals in Buddhist \\ temple Honpa Honganji in Londrina
}

Leonardo Henrique Luiz ${ }^{1}$

Richard Gonçalves André ${ }^{2}$

RESUMO

O Bon Odori é um rito mortuário inerente ăo Budismo japonês que, realizado durante o "Festival dos Finados", objetiva permitir que os seres consigam transmigrar para diferentes dimensões das esferas budistas. Neste artigo, pretende-se analisar o ritual ligado ao templo budista Honpa Honganji, situado em Londrina (Paraná). Como metodologia, foram feitas observações participantes do Bon Odori no ano de 2014 e entrevistas com o monge budista local. Da perspectiva teórica, são utilizados os conceitos de campo religioso e apropriação, propostos, respectivamente, por Pierre Bourdieu e Roger Chartier. A partir disso, é sugerido que, embora constitua um rito mortuário, elementos do universo "profano", bem como distintos atores sociais, teriam sido associados ao Bon Odori. Essa mudança seria gerada pela necessidade desse Budismo, que permanece no Brasil uma religião étnica, desenvolver estratégias de proselitismo que lhe permita angariar novos fiéis, inclusive fora do círculo de imigrantes japoneses e descendentes, para sua reprodução social.

Palavras-chave: Bon Odori. Budismo. Proselitismo. Honpa Honganji. Londrina.

\section{ABSTRACT}

Bon Odori is a mortuary rite related to Japanese Buddhism that, held during the "Festival of the Deceased", aims to allow the beings to transmigrate to different dimensions of Buddhist spheres. This paper intends to analyze the ritual connected to the Honpa Honganji Buddhist temple, located in Londrina (Paraná). As methodology, participant observations of Bon Odori were made in 2014 and interviews with the local Buddhist monk. From theoretical perspective, it is used the concepts of religious field and appropriation, suggested, respectively, by Pierre Bourdieu and Roger Chartier. From this, it is suggested that, although it is a mortuary rite, elements of "profane" universe, as well as distinct social actors, have been associated with Bon

\footnotetext{
1 Mestrando do Programa de Pós-Graduação em História Social da Universidade Estadual de Londrina (UEL). Bolsista da Fundação Araucária. E-mail: leonardo_luiz8@hotmail.com

2 Doutor em História pela Universidade Estadual Paulista (UNESP) e professor do Departamento de História da Universidade Estadual de Londrina (UEL). É coordenador do Grupo de Pesquisas sobre Religiões e Religiosidades Orientais (GPERRO)CNPq. E-mail: richard.historia@gmail.com
} 
Odori. This change would be created by the need of this Buddhism, which remains in Brazil an ethnic religion, to develop strategies of proselytism that enable it to acquire new faithful, including outside the circle of Japanese immigrants and descendants, to its social reproduction.

Keywords: Bon Odori. Buddhism. Proselytism. Honpa Honganji. Londrina.

\section{Passos Iniciais}

O Bon Odori (literalmente, "Dança dos Finados"), realizado anualmente pelo templo budista Honpa Honganji em Londrina (Paraná), é uma cerimônia religiosa de caráter mortuário marcada por certa animosidade, envolvendo músicas, danças, alimentos e decoração específica. Paralelamente ao caráter festivo do ritual, que ocorre sobretudo no pátio, no interior do templo incensos são queimados diante das estátuas do Buda Amida e de dois patriarcas da religião, Shinran e Rennyo, sobre os quais se discorrerá mais adiante.

A queima dos incensos remete às representações e às práticas mortuárias ligadas ao Bon Odori. Todavia, mesmo os elementos aparentemente profanos sugeridos (música, dança, decoração e gastronomia particulares da cerimônia) fazem parte do rito, na medida em que a celebração da morte seria prática coletiva e "domesticada" no interior das religiões e religiosidades nipônicas ${ }^{3}$, em contraposição ao tabu da morte que começou a ser estruturado na Europa desde o século XVIII (ARIÈS, 1989). Considerando a complexidade que perpassa o fenômeno em foco, o objetivo do presente artigo é analisar o Bon Odori praticado no templo budista Honpa Honganji, situado em Londrina, no Norte do Paraná, sugerindo que diversos elementos apropriados ao repertório do ritual no templo em questão fazem parte de estratégias de proselitismo religioso com o intuito de atrair novos membros. É preciso perceber que o Budismo japonês em Londrina, voltado especialmente para a Verdadeira Escola da Terra Pura (Jôdô Shinshû浄土真宗) ${ }^{4}$, é uma religião étnica ${ }^{5}$ que, com a progressiva morte dos membros da comunidade, enfrentaria desafios para sua reprodução social, demandando por práticas diferenciadas.

Para a análise, foram feitas observações participantes durante o Bon Odori realizado nos dias 16 e 17 de agosto de 2014 no Templo Honpa Honganji. Não obstante as distâncias

\footnotetext{
3 Mesmo que o Budismo, a rigor, seja uma religião indiana, parte de seu desenvolvimento, como será discutido, foi realizado em território japonês. Por isso, quando são utilizadas as expressões "religião" e "religiosidade" japonesas, também são concebidas as manifestações budistas.

4 Fundadas no século XIII no Japão, as escolas da Terra Pura são voltadas para a devoção do Buda Amida, principalmente por meio da recitação do Nenbutsu ("namu amida butsu", "eu reverencio o Buda Amida") (GONÇALVES, 1971).

5 Quando se fala aqui em religião étnica, aborda-se especificamente as práticas relacionadas ao templo Honpa Honganji. É importante ressaltar que, inclusive em Londrina, templos de outras escolas, como é o caso do Hompoji (ligado à chamada Honmon Butsuryû Shû), apresentam uma melhor acomodação cultural entre não descendentes.
} 
sociais e culturais dos pesquisadores, que não podem ser totalmente obliteradas numa interpretação objetiva do fenômeno circunscrito, espera-se que a observação participante tenha permitido perscrutar melhor a densidade de significados inerente ao ritual (GEERTZ, 2008). Foram produzidos, nesse sentido, materiais como cadernos de campo (ANDRÉ, 2014a) e fotografias. Em determinados pontos do artigo, optou-se por uma descrição pormenorizada dos rituais para sua melhor compreensão, considerando, além disso, a escassez de referências em língua portuguesa sobre o Bon Odori (abordado de forma pontual por pesquisadores como Marcelo Alario Ennes [2001]), cerimônia aparentemente negligenciada pela historiografia sobre as religiões japonesas no Brasil6.

Além disso, outra fonte utilizada é uma entrevista feita por Richard Gonçalves André (2014b) com o monge à frente do templo, Genyû Katata, no dia 23 de maio de 2014. A entrevista teve caráter semiaberto, estruturada a partir de um questionário flexível concebido pelo entrevistador, de forma que o depoente pudesse construir sua narrativa com o mínimo de intervenções por parte do pesquisador. A entrevista teve cunho temático, sendo voltada, portanto, para temas de interesse mais ou menos específicos (ALBERTI, 2011). O depoimento foi gravado em vídeo, sendo, posteriormente, transcrito.

Como fundamentação teórica, foi utilizado o conceito de campo religioso proposto pelo sociólogo francês Pierre Bourdieu (2005), cujo sentido remete a um espaço simbólico dotado de regras ou convenções religiosas mais ou menos específicas prescritas pelos especialistas dos bens de salvação, como os monges à frente dos templos. Dotados de capital religioso ou autoridade pelos fiéis, os líderes definiriam a forma apropriada de interpretar e praticar as prescrições religiosas (embora, a rigor, a apropriação nunca possa ser totalmente controlada [CHARTIER, 2002]), demarcando, portanto, as possíveis fronteiras com outros campos voltados para a lide com o sagrado. Entretanto, compreende-se aqui que o Budismo do Honpa Honganji, estabelecido em Londrina desde 1950, ainda não constitui um campo fechado, na medida em que tem dialogado de diferentes formas como as mudanças históricas da comunidade nikkei ${ }^{7}$ na cidade.

Relacionado ao campo religioso, foi utilizado também o conceito de apropriação, tendo em vista as proposições teóricas do historiador francês Roger Chartier (2002). Para o autor, o leitor nunca permanece passivo no processo de leitura, na medida em que se apropria seletivamente de determinados aspectos do texto e, inclusive, constrói sentidos que poderiam não ter sido previstos pelos produtores. No entanto, é possível compreender o 
texto em sentido lato, envolvendo não apenas as produções escritas, mas também outras formas de linguagem, incluindo-se as religiões como um todo em suas diferentes manifestações, embora Chartier não tenha refletido sobre as representações e as apropriações a partir do fenômeno religioso. De qualquer forma, elementos que compõem determinados sistemas religiosos, como símbolos e ritos, podem ser apropriados por diferentes religiões, como é o caso da própria Verdadeira Escola da Terra Pura em Londrina, como será discutido mais adiante.

\section{Mortos que Voltam no Japão}

O mito de origem (ELIADE, 2001) que fundamenta o Bon Odori seria a narrativa de um discípulo do Buda Histórico, Sakyamuni, chamado Mokuren ${ }^{8}$. Após a morte de sua mãe, ele teria sido capaz de enxergá-la na dimensão dos "espíritos" famintos (ANDRÉ, 2014b). No interior do imaginário budista, o espírito encontra-se preso num ciclo de mortes e renascimentos denominado samsara, movido, por sua vez, pelo carma que seria o reflexo das ações individuais ao longo desta e de outras vidas. Contudo, o renascimento poderia ocorrer em diferentes dimensões, algumas inclusive divinas, que não marcariam ainda o estágio final de evolução (ELIADE, 2011). O mundo dos espíritos famintos seria um universo de sofrimentos físicos voltados, principalmente, para a sede e a fome. A libertação do samsara seria possível apenas com a destruição do círculo cármico, de modo que o ser pudesse alcançar o parinirvana, que seria a libertação das amarras do ego (ELIADE, 2011), embora a definição de parinirvana na literatura budista, principalmente no chamado Cânon Páli ${ }^{9}$, seja vaga. Retornando à narrativa de Mokuren, considerando a situação de sua mãe na dimensão dos espíritos famintos, ele teria perguntado a Sakyamuni uma forma de elevála a outros círculos que aliviassem seu sofrimento. O Buda Histórico teria sugerido, então, que o discípulo reunisse os outros monges e realizassem um banquete com músicas e dança. Feito isso, a mãe teria conseguido transmigrar para outros mundos (ANDRÉ, 2014b).

É válido ressaltar que a mitologia do Bon Odori faz parte da vertente Mahayana do Budismo que se desenvolveu, sobretudo, em regiões como China e Índia. O Mahayana ou "veículo do grande caminho", em contraposição ao Hinayana ("veículo do pequeno

8 O Buda Histórico é a forma como é chamado Sidarta Gautama ou Sakyamuni, o fundador do Budismo na Índia do século VI a.C. (ELIADE, 2011). No entanto, de acordo com textos posteriores, teria havido outros budas anteriores a Sakyamuni. Um deles seria Amida, cultuado como uma divindade que residiria numa espécie de paraíso denominado Jôdo ou Terra Pura (AMIDAKYO..., 2004; BUDISMO..., 2013).

9 O Cânon Páli ou Budista, originalmente Tripitaka (os "três cestos"), diz respeito ao conjunto de escritos em língua páli realizados pelos discípulos do Buda Histórico. A documentação do Cânon Páli ocorreu sistematicamente cerca de seiscentos anos após o falecimento de Sakyamuni (BUDISMO..., 2013). Em português, fragmentos do Cânon Páli foram disponibilizados por R. M. Gonçalves (1993b) e Nissim Cohen (2008). 
caminho"), é um ramo que, originado da Índia, remete a uma flexibilização das concepções e práticas, mais abertas à comunidade leiga. O Hinayana desenvolve práticas rigorosas voltadas para alcançar a lluminação acessível talvez apenas à comunidade monástica, na medida em que os leigos seriam responsáveis quase exclusivamente pela manutenção dos monges (WEBER, 1958). Além disso, os mahayanistas questionavam o fato dos monges permanecerem, teoricamente, fechados aos problemas do mundo ${ }^{10}$. Ganhando certa popularidade no seio da população, o Mahayana passou a apropriar, em território chinês e japonês, uma série de elementos da religiosidade nativa, a tal ponto que certos boddhisatvas (indivíduos que teriam alcançado a iluminação em vida, condição fundamental para libertar-se do samsara, mas decidindo permanecer renascendo com o intuito de salvar todos os seres [WEBER, 1958]), como Kannon ${ }^{11}$, passaram a ganhar certo caráter divino e salvacionista (GONÇALVES, 1993a). Mesmo concepções paradisíacas (provindas da Pérsia, segundo R. M. Gonçalves [1993a]) tornaram-se parte do repertório do Mahayana, como o Jôdô ou Terra Pura, que sugeria um local governado por Amida no qual haveria abundância de vegetação, caudalosidade de rios e joias cintilantes (AMIDAKYO..., 2004) ${ }^{12}$. Elementos basilares do mito do Bon Odori, como o sofrimento da mãe de Mokuren na dimensão dos espíritos famintos, praticamente não fazem parte do Budismo indiano de caráter Hinayana. É válido lembrar que o Buda Histórico, na medida do possível, teria evitado debates de cunho metafísico (ELIADE, 2011), que tinham raízes no Brahmanismo e no Hinduísmo (embora também não os tenha rejeitado), bem como não deixou prescrições mortuárias quando da iminência de sua morte, a despeito da preocupação de seus discípulos (GONÇALVES, 1971).

No Japão, o Bon Odori é realizado na conjuntura do Obon Matsuri (お盆踊り, "Festival dos Finados"), comemorado a partir do dia 15 de agosto. No período, acredita-se que os espíritos dos ancestrais retornariam do mundo espiritual, exigindo uma série de ritos especiais nos relicários domésticos denominados butsudan (literalmente, "altar dedicado aos budas"), nos túmulos e nos templos budistas (FUJII, 1983). Alguns ramos budistas, como a

10 Entretanto, é válido ressaltar que a expressão "Hinayana" implica sentido pejorativo (EPSTEIN, 1999), uma vez que seria o "veículo do pequeno caminho", conservador do ponto de vista doutrinário e prático, em detrimento do "grande caminho" inaugurado pelo Mahayana, de caráter mais amplo ao envolver de fato os leigos, a preocupação com os problemas do mundo e a apropriação de diferentes concepções religiosas. A palavra passou a ser utilizada posteriormente para referir-se a certas escolas mais tradicionais, do ponto de vista dos adeptos do Mahayana, como a Theravada, fundada no Sri Lanka (EPSTEIN, 1999).

11 Kannon tornou-se uma entidade no imaginário budista reverenciada como uma divindade, sendo a personificação da compaixão por todos os seres (DYKSTRA, 1976).

12 Embora a Terra Pura possa ser considerada uma metáfora que remete à iluminação (ou, talvez, ao parinirvana), é possível que, entre as camadas populares das sociedades indiana, chinesa e japonesa, o Jôdô tenha sido pensado em sua materialidade, como recompensa post mortem às ações neste mundo. Não é coincidência que, para as escolas de Terra Pura, a recitação do Nenbutsu seja condição para a entrada na Terra Pura. De qualquer forma, a concepção de Jôdo poderia variar de acordo com a escola budista em foco. 
Escola Shingon ${ }^{13}$, chegam a realizar um ritual ao final do Obon Matsuri denominado Tôrô Nagashi, em que são confeccionados pequenos barcos nos quais são escritos os nomes dos ancestrais. Os artefatos são deixados em lagos, rios e mares, simbolizando o retorno dos espíritos ao mundo dos mortos (ANDRÉ, 2011b; sobre a especificidade do Shingon na execução do rito, ANDRÉ, 2014b). No Brasil, poucos locais, como a cidade paulista de Carlópolis, realizam o Tôrô Nagashi.

Retornando ao Bon Odori, de acordo com o mito de origem fundamentado na narrativa de Mokuren, trata-se de um ritual mortuário com o objetivo de permitir que os espíritos consigam transmigrar para outros círculos espirituais, aliviando seus possíveis sofrimentos. No entanto, é válido ressaltar que, no Japão, ele foi ressignificado, na medida em que o retorno dos mortos ao universo dos viventes parece diferente das representações do Budismo indiano voltado para a questão do samsara alimentado pelo princípio cármico. Como indicado, a devoção ao Buda Amida ou Amidismo, representado em território japonês pelas escolas de Terra Pura, é arquitetada sobre a crença num paraíso post mortem, de modo que o princípio do samsara, elemento fundamental do Hinayana, parece não fazer parte de seu repertório (ANDRÉ, 2014b) ${ }^{14}$. De qualquer forma, no Bon Odori, são feitas danças circulares em torno de indivíduos que tocam tambores (taiko), utilizando movimentos baseados em atividades cotidianas (como a colheita e a pesca). Essa circularidade, como será discutido mais adiante, parece remeter à ideia de eterno retorno ao tempo mítico e ao caráter circular do imaginário budista. Embora haja pessoas mais ou menos especializadas na dança e que a iniciam, todas as outras, vestidas ou não a caráter, podem entrar na roda e participar da cerimônia, não se tratando, portanto, de um ritual voltado apenas para os iniciados e sob o olhar atento dos monges.

A animosidade que marca o Bon Odori pode levar à impressão de que a morte é apenas festejada com cantoria, dança e banquetes. Isso não quer dizer que os japoneses não sintam pesar pelos falecidos. Trata-se, antes, de uma concepção de morte relativamente estranha ao Ocidente na atualidade, na medida em que, desde o século XVIII, ela tornou-se tabu, devendo ser evitada, não se falando sobre a mesma para evitar constrangimento e dor aos amigos, parentes e, principalmente, ao moribundo. A vida é esticada por meio das técnicas do mundo moderno, mesmo agonizando em hospitais por meio de tubos ligados a tanques de oxigênio (ARIÈS, 1989). No Japão, mesmo causando

13 A Escola Shingon foi fundada no Japão no século IX d.C. pelo monge Kûkai, que viajou para a China para conhecer esse ramo do Budismo. Uma de suas principais práticas é a recitação de um mantra (um conjunto de sons que, uma vez recitados, possuiriam poder espiritual), denominado Kômyô Shingon, o "Mantra da Luz" (UNNO, 2004).

14 Mesmo assim, o Bon Odori não é exclusividade das escolas de Terra Pura, sendo realizado em templos de diferentes vertentes budistas no Japão. A concepção devocional, salvacionista e mesmo paradisíaca que caracteriza as escolas da Terra Pura parece fazer parte de um fundo comum que perpassa a apropriação do Budismo em território japonês. 
tristeza, a morte é domesticada, apropriando a expressão utilizada por Ariès (1989), porquanto sua hora certa deva ser respeitada, propiciando um bem morrer. A morte ruim é aquela que ocorre fora do momento adequado, precoce ou tardiamente, longe de casa ou gerada por circunstâncias violentas, como incêndios, afogamentos, abortos e outros infortúnios, levando, no imaginário nipônico, ao surgimento de espíritos instáveis que, não convertidos em ancestrais, poderiam causar malefícios aos viventes (WIJAYARATNA, 1997). O "bom morto", entenda-se o ancestral ou senzo, não é relegado apenas ao templo ou ao cemitério, sendo reverenciado no interior da casa no altar budista. Parte de suas cinzas, inclusive, pode permanecer em esfera doméstica, marcando uma distância pequena entre o mundo dos vivos e dos mortos. No Ocidente, os trespassados são exorcizados da casa, relegados à esfera pública do cemitério ou da igreja; no Japão, eles são evocados para o seio do lar, convertendo-se em ancestrais protetores dos vivos ${ }^{15}$.

Além disso, a animosidade que marca os ritos mórbidos no Budismo nipônico remete à própria concepção material de morte. Os ancestrais estariam mais ou menos presentes no universo dos viventes (mesmo, paradoxalmente, fora do período do Obon Matsuri), possuindo "necessidades" que deveriam ser atendidas em troca da proteção oferecida à família. Como afirma G. B. Sansom (1973, p. 114),

[...] Desde que os mortos existem, seus desejos também devem ser atendidos. Oferendas devem ser feitas a eles, de comida e água, e seus desejos devem ser verificados e seguidos. Assim, uma criança póstuma deve ser anunciada ao túmulo, ou para as tabuletas memorais do pai, uma noiva deve ser apresentada para os antepassados do noivo. Aqui nós temos os fundamentos do culto aos ancestrais. Para as famílias, os mortos não estão mortos: eles devem ser consultados, confortados e reverenciados. ${ }^{16}$

Não se tratam, portanto, de mortos "etéreos" que estariam longe, mas de ancestrais presentes em sua manifestação quase física, como sugere Sansom. Parte dessas concepções mortuárias, provavelmente, constitui apropriações mais ou menos tardias que o

15 No entanto, é preciso relativizar as distâncias culturais entre as concepções de morte ocidentais e orientais. Em primeiro lugar, o discurso médico e higienista que passou a tratar o morto do ponto de vista científico, buscando deslegitimar o papel das religiões em sua lide, somente começou a se popularizar no Brasil a partir do século XIX (REIS, 1991). Acontecimento emblemático nesse sentido seria a Cemiterada, revolta ocorrida em Salvador em 1836, na qual parte da população da cidade invadiu o Cemitério do Campo Santo, destruindo-o parcialmente como manifestação às proibições de enterro dos defuntos nas igrejas (REIS, 1991). Além disso, mesmo após o desenvolvimento do imaginário higienista, certas práticas mortuárias "domesticadas" permaneceram em algumas regiões do Brasil, tais como os velórios no interior das casas (MARTINS, 1983), os cortejos fúnebres e os cultos aos mortos nos cemitérios (VALLADARES, 1972). Por fim, é válido ressaltar a proximidade com a qual a morte é abordada nas religiões afro-brasileiras (ORTIZ, 1983).

16 No original, "[...] Since the dead exist, their wants must be attended too. Offerings must be made to them, of food and drink, and their wishes must be ascertained and followed. Thus a posthumous child must be announced to the bier, or to the memorial tablets of its father, a bride must be presented to the bridegroom's ancestors. Here we have the fundamentals of ancestor worship. For the purposes of the family, the dead are not dead: they must be consulted, comforted and revered." $E$ válido ressaltar que a tradução de bier, em inglês, pode remeter tanto a féretro quanto ao carro fúnebre. No caso, Sansom parece remeter ao túmulo, não ao caixão propriamente dito. No entanto, no Budismo japonês, a tabuleta memorial (ihai) seria uma miniatura da sepultura, inserida por sua vez no butsudan (que seria a miniaturização do templo budista). Por isso, fica ambíguo se o autor está se referindo ao túmulo no cemitério ou aos artefatos no oratório doméstico. 
Budismo Mahayana realizou em território chinês e, posteriormente, japonês, agregando de forma ressignificada os elementos religiosos locais e mesmo traços do Confucionismo (SANSOM, 1973). Segundo a piedade filial prescrita por Confúcio (2007) e seus intérpretes, os pais deveriam ser incondicionalmente reverenciados na vida e, também, na morte por meio dos ritos fúnebres pertinentes.

\section{O Budismo em Londrina}

O Budismo japonês começou a se consolidar institucionalmente no Brasil a partir da segunda metade do século XX (MAEYAMA, 1967, 1973a). Isso não quer dizer que, desde 1908, quando da vinda oficial das primeiras famílias nipônicas para o território brasileiro, não tenha havido práticas que remetam a formas de religiosidade como o culto doméstico aos ancestrais, as devoções cemiteriais, o curandeirismo, os grupos de oração e as atividades de monges e substitutos de monges (bôzu gawari) que, sem formação propriamente religiosa, passaram a desenvolver práticas religiosas no país (MAEYAMA, 1967; ANDRÉ, 2011a, 2011b; NAKAMAKI, 1993). No entanto, nas primeiras décadas de imigração, houve diversos obstáculos que dificultaram o desenvolvimento das religiões japonesas na sociedade receptora. Dentre eles, pode-se destacar as exigências do governo e das companhias japonesas de imigração no sentido dos nikkeis não desenvolverem proselitismo religioso (com exceção do Catolicismo) fora do Japão (LESSER, 2001); a mobilidade espacial dos trabalhadores nipo-brasileiros em razão do regime de trabalho baseado no colonato, o que dificultava um maior enraizamento cultural (ANDRÉ, 2011b) e, entre outras razões, os discursos e as práticas antinipônicos de cunho racista e militarista que circulavam na primeira metade do novecentos, principalmente durante a conjuntura da Segunda Guerra Mundial (ANDRÉ, 2011b).

$\mathrm{Na}$ segunda metade do século $\mathrm{XX}$, principalmente nos estados de São Paulo e Paraná, houve condições de emergência para a institucionalização das religiões japonesas como campos religiosos, isto é, o desenvolvimento de elementos como templos, sacerdotes, fiéis, liturgias, entre outros aspectos (BOURDIEU, 2005). Os nikkeis passaram por um processo de ascensão social, como sugerem pesquisadores como Takashi Maeyama (1973b), tornando-se pequenos proprietários (e não apenas colonos), permitindo um maior enraizamento territorial e cultural. Isso é particularmente pertinente em regiões constituídas por nipo-brasileiros, como a cidade norte-paranaense de Assaí (fundada por uma empresa nipônica, a Brasil Takushoku Kumiai ou BRATAC [HANDA, 1987; ASARI, 1992; SATO, 1999]), ou com forte presença nikkei, como Londrina, mesmo ao lado de outras etnias como 
italianos e alemães. Parece ter havido também um progressivo esmaecimento em relação aos discursos e às praticas antinipônicos, embora não seja possível dizer que certa desconfiança em relação à comunidade nipônica tenha desaparecido completamente.

Na região que viria a tornar-se Londrina, lembrando que o município foi constituído em 1934, a presença de famílias nikkeis pode ser verificada desde 1929, quando os primeiros japoneses e descendentes compraram lotes da Companhia de Terras Norte do Paraná (CTNP). A empresa, subsidiária da Paraná Plantations, era financiada por capital inglês e, na conjuntura, comprou terras do Estado em parte do Norte do Paraná com o intuito de comercializá-las, principalmente, para pequenos e médios proprietários (TOMAZI, 2000). Lotes fundiários foram vendidos não apenas para brasileiros, mas para reimigrantes (e, no caso da Gleba Roland, que daria origem à cidade de Rolândia em 1943 [IBGE, s.d.], imigrantes judeus e alemães [SOARES, 2009]) de diferentes etnias que, em parte, já haviam imigrado para o Brasil na condição de colonos no interior do sistema de colonato. Portanto, não se tratavam de imigrantes diretos, mas de reimigrantes.

Os nikkeis passaram a comprar propriedades rurais em regiões vizinhas uns aos outros, buscando recriar em território londrinense certas formas de organização existentes no Japão, como o sistema de mura ou kumi na Colônia Internacional, como era chamada Londrina pelos nipo-brasileiros em razão da sugerida multiplicidade étnica (MAESIMA, 2012). Os kumi seriam, portanto, microrregiões que existiam apenas no interior da comunidade nipônica. Cada qual possuía um representante denominado kumichô, que seria responsável pela organização das atividades da seção, devendo responder pela mesma para a comunidade de forma geral, principalmente por meio de agremiações nipo-brasileiras como a Associação Cultural e Esportiva de Londrina (ACEL) (MAESIMA, 2012).

Os kumi ofereceram condições, portanto, para o surgimento de microrregiões marcadamente japonesas em Londrina. Uma delas é a atual Vila Shimabokuro, situada na parte Oeste de Londrina, onde ainda hoje é possível observar residências com características arquitetônicas que lembram as casas japonesas, havendo, inclusive, em algumas de suas fachadas brasões familiares denominados kamon. É possível que, durante o período em que o Brasil participou da Segunda Guerra Mundial, em que houve o recrudescimento dos discursos e das práticas antinipônicos, na medida em que os japoneses foram considerados "súditos do Eixo" ou "quinta coluna" (LESSER, 2001; TAKEUCHI, 2001; SETO; UYEDA, 2002; ANDRÉ, 2011b), os kumi tenham sido vistos como espaço de desconfiança na sociedade brasileira. Afinal, constituíam unidades nas quais se tentou reconstruir certos elementos da organização social, política e territorial japonesa, havendo escolas e associações, entre outros aspectos. A cidade de Assaí, por exemplo, era 
vista como "quisto étnico" pernicioso não apenas pelas autoridades brasileiras, como também por indivíduos não descendentes que residiam na região (DELEGADO..., 1948), lembrando que um dos dispositivos utilizados em conjuntura de guerra era a delação (TAKEUCHI, 2001).

Talvez não seja coincidência, nesse sentido, que as religiões japonesas tenham se consolidado apenas a partir da segunda metade do século XX como campos institucionais no Brasil de maneira geral e, em particular, em Londrina ${ }^{17}$. A construção do templo budista Honpa Honganji, situado justamente na Vila Shimabokuro, foi concluída no dia 3 de dezembro de 1950, conforme inscrições num monumento em pedra conservado no pátio do templo. O templo constitui parte essencial do ensinamento budista, implicando na organização social da comunidade em torno do mesmo. Nissim Cohen (2008) explica que, para os seguidores de Buda, existiriam as Três Joias: o Buda, o darma e o sangha. A palavra sangha é traduzida como comunidade ou assembleia, sendo um lugar onde o fiel busca refúgio espiritual, ou seja, um grupo de pessoas que se apoiam mutuamente. Desse modo, o templo budista como manifestação da religiosidade nipônica pode ser compreendido como forma de resistência, uma vez que é local considerado sagrado na organização da comunidade nipônica e representa símbolo de conquista para a manutenção da religiosidade nikkei. Voltando ao caso do Honpa Honganji, a arquitetura teria seguido estilo tradicional, baseada no encaixe de tábuas e sem a necessidade de pregos (MAESIMA, 2012). É presumível que as obras tenham sido fruto do trabalho coletivo dos membros de vários kumi, num sistema corporativo de auxílio mútuo característico da organização social japonesa que pode envolver a construção de casas, escolas, a realização de gincanas (undôkai) e outras festividades.

Além disso, a templarização institucional concretizou uma série de práticas anteriores realizadas por grupos de oração e monges leigos que atendiam às demandas religiosas de nikkeis que se encontravam estabelecidos em Londrina, então, há duas décadas (no caso da cidade paulista de Lins, ver as considerações de Hitorika Nakamaki [1993]). No caso do Honpa Honganji, havia um leigo chamado Mankichi Nakatsukasa que desempenhava o papel de leitor de sutra antes da chegada do monge japonês propriamente dito, conforme entrevista realizada com sua neta Elminha Kazumi Tokairin (2017). É válido lembrar o papel que o Budismo assumiu nos ritos mortuários japoneses, de tal forma que a ocorrência da morte deveria ser mediada por especialistas religiosos com o intuito de converter os 
falecidos em ancestrais, como sugerido por Masao Fujii (1983). Em Londrina, tendo em vista o estabelecimento precoce dos nikkeis como pequenos proprietários fixados à terra e buscando reconstruir elementos sociais, políticos, territoriais e religiosos existentes no Japão, os indivíduos pertencentes à comunidade nikkei, tal como em outras regiões do país, lançaram mão de substitutos de monges e "leitores de sutras" (okyô yomi) ${ }^{18}$ para a lide com os ritos fúnebres quando da ausência de monges propriamente ditos. Esses monges leigos, em certas regiões do país, ganharam importância significativa ao atender às necessidades espirituais de imigrantes e descendentes que, longe de sua terra natal, não dispunham sistematicamente de especialistas religiosos que, no Japão, mediavam o universo dos vivos e dos mortos (MAEYAMA, 1967).

O caráter étnico do Budismo no templo Honpa Honganji parece ser um dos elementos basilares desde o período de estruturação do templo. Em consonância com as observações de Usarski (2002) acerca de outras regiões do país, as práticas budistas londrinenses de Terra Pura têm sido marcadas pela presença de nikkeis, tratando-se do que o autor chama de "Budismo de imigração" (USARSKI, 2002, p. 10), tendo ainda pouco apelo como religião universal. $O$ quadro é diferente quando se pensa em outras religiões japonesas como a Seichô-no-ie que, com o passar do tempo, desenvolveram estratégias mais ou menos eficazes no sentido de angariar praticantes e mesmo corpo sacerdotal composto de não descendentes (ALBUQUERQUE, 1999). No caso do Budismo de imigração, segundo Usarski (2002, p. 16), “[...] Até hoje faltam estratégias missionárias adequadas, o que explica porque nos templos japoneses há uma desproporção significativa entre afiliados de origem japonesa e outros brasileiros. [...]". Em termos estatísticos, Usarski (2008) aponta para a existência de um decréscimo na quantidade de budistas declarados no censo do IBGE entre 1991 e $2000^{19}$.

Cientes dos desafios enfrentados pelo Budismo japonês no Brasil, as autoridades da Verdadeira Escola da Terra Pura começaram a desenvolver uma série de estratégias para divulgar a religião em língua portuguesa, como a publicação de jornais (ver, por exemplo, JORNAL, 2013a, 2013b) e a realização de eventos. Mesmo nos Estados Unidos, que recebeu significativa quantidade de imigrantes japoneses até o início do século $\mathrm{XX}$, os templos Honganji têm buscado formas de transcender o caráter étnico, tentando criar mecanismos para transformar o Budismo nipônico numa religião universal (STREAMS...,

18 Sutras são os textos que fazem parte do Cânon Páli. Alguns deles são lidos durante as cerimônias fúnebres, daí o papel desempenhado pelos leitores de sutras, os substitutos de monges na falta destes.

19 Para dados precisos, ver Usarski (2008, p. 138), que organiza os dados a partir dos censos de 1970, 1980, 1990 e 2000, acompanhando as transformações no número de praticantes budistas de "cor amarela", de "cor não-amarela" e da quantidade total. 
2013). Portanto, os problemas enfrentados pelas escolas de Terra Pura não possuem apenas âmbito local, envolvendo uma dimensão nacional e mesmo internacional ${ }^{20}$.

Voltando ao caso do Honpa Honganji em Londrina, há três características marcadamente étnicas. Em primeiro lugar, mesmo hoje, durante os ritos, a recitação dos sutras e boa parte dos comentários continua sendo realizada em língua japonesa, dificultando para o não descendente (e mesmo para os descendentes de terceira e quarta geração, que têm falado cada vez menos a língua dos avós [COMISSÃO DE RECENSEAMENTO DA COLÔNIA JAPONESA, 1969; SATO, 1999]) a compreensão do conteúdo ministrado. Corolário da questão anterior, a maioria dos adeptos é constituída de nikkeis pertencentes às famílias que frequentam o templo, havendo poucos não descendentes. Por fim, todos os onze monges à frente do Honpa Honganji (de acordo com as fotografias dispostas no interior do templo durante o Obon Matsuri) desde sua fundação são nikkeis ou, às vezes, japoneses propriamente ditos. É importante ressaltar o último aspecto na medida em que outras escolas budistas, como o Templo Hompoji em Londrina (ligado à escola Nichiren) ${ }^{21}$, possuem monges brasileiros que pregam em língua portuguesa.

Em razão do caráter étnico do Budismo Honpa Honganji em Londrina, ele parece enfrentar certos desafios, uma vez que os membros de primeira e segunda geração estão progressivamente falecendo. É válido ressaltar que, de forma geral, embora para a primeira geração a reconstrução de certos elementos da cultura pré-migratória fosse importante, para as demais a integração à sociedade brasileira era essencial, mesmo porque esses nikkeis não eram mais japoneses, mas civilmente brasileiros, embora suas identidades, de diferentes maneiras, estivessem alicerçadas ao Japão. Os membros de segunda geração começaram a trabalhar e estudar fora da propriedade rural japonesa (lembrando que os filhos mais velhos, teoricamente, seriam herdeiros dos bens econômicos e simbólicos do patriarca [BENEDICT, 1972]), criando redes de sociabilidade com não descendentes, seja por meio da educação ou por casamentos interétnicos (LESSER, 2001). Diversos indivíduos da terceira geração, como afirmado, não falam japonês ou o compreendem muito pouco, criando um hiato geracional importante para a explicação do fenômeno em questão (ANDRÉ, 2011b). Já em 1969, no sistemático levantamento estatístico feito pela Comissão de Recenseamento da Colônia Japonesa (1969), pode-se perceber um declínio dos falantes de japonês, o que é diretamente proporcional à diminuição dos adeptos das religiões

20 No caso de Brasília, por exemplo, Regina Y. Matsue (2002) analisa como as barreiras linguísticas e culturais foram superadas para alcançar membros não nikkeis, existindo inclusive a presença de nativos nas funções monásticas.

$21 \mathrm{Tal}$ como as escolas de Terra Pura, o Budismo Nichiren foi fundado em território japonês no século XIII. Por meio da recitação do Daimoku, "namu myôhô renge kyô" ("eu dedico minha vida à Lei do Sutra do Lótus"), seria possível o indivíduo encontrar a salvação, mesmo teoricamente um bandido (GONÇALVES, 1971). 
japonesas e inversamente proporcional ao crescimento de nikkeis frequentando as religiões "ocidentais", principalmente o Catolicismo.

Tabela 1 - Distribuição estatística da opção religiosa a partir da linguagem

\begin{tabular}{|c|c|c|c|c|}
\hline & Total & Português & $\begin{array}{c}\text { Português e } \\
\text { japonês }\end{array}$ & Japonês \\
\hline Católicos & 5.703 & 1.883 & 2.271 & 1.549 \\
\hline Budistas & 4.819 & 241 & 1.488 & 3.090 \\
\hline
\end{tabular}

Fonte: Comissão de Recenseamento da Colônia Japonesa (1969, p. 304).

Conforme a tabela 1, apesar dos dados corresponderem ao ano de 1969, envolvendo - Brasil como um todo, as estatísticas levantadas pela comissão sugerem tendências importantes para pensar múltiplos aspectos da organização social nikkei, inclusive no tocante à religião tendo como critério a opção linguística. Na tabela, foram desconsideradas as categorias relativas aos espíritas, sincréticos com o Catolicismo, protestantes, sem religião, sincréticos sem Catolicismo, xintoístas e novas religiões (segundo a nomenclatura do próprio documento), na medida em que constituem minoria numérica. Foram mantidos apenas os católicos e os budistas, mais expressivos. Como visto, no caso dos católicos, há uma relativa aproximação entre os falantes de português (1.883) e japonês (1.549), enquanto que no Budismo existe uma grande distância: apenas 241 indivíduos falam português, ao passo que 3.090 apenas a língua japonesa. Entre católicos e budistas, os bilíngues teriam condições de escolher uma das religiões, embora a maioria dos primeiros (5.703), comparados aos 4.819 budistas, possa indicar o peso dos projetos de catequização realizados pela Igreja desde os anos 1930 (YOKOYAMA, 1998), bem como as restrições às religiões japonesas no Brasil22.

Diante dessa situação, em Londrina, nos últimos anos, é perceptível a criação de estratégias para a divulgação dos preceitos e práticas da Verdadeira Escola da Terra Pura, o que constitui elemento relativamente novo em seu repertório. De uma religião calcada na tradição familiar e endógena, busca-se um proselitismo com o intuito de atrair novos membros, inclusive não descendentes, de forma exógena, embora pareça não haver ainda resultados expressivos nesse sentido.

No bojo dessas estratégias, pode-se destacar o próprio perfil do monge atualmente à frente do Honpa Honganji, Genyû Katata. Trata-se de um jovem monge vindo do Japão que reside no Brasil há doze anos, tendo trabalhado no templo matriz em São Paulo, deslocando-se, posteriormente, para Presidente Prudente (SP), vindo para Londrina há sete 
anos. Katata fala pouco a língua portuguesa, que, quando possível, é utilizada nos ritos por ele realizados em ocasiões pontuais, geralmente após a recitação dos sutras e durante os comentários. Mesmo assim, grande parte do rito é feito em japonês. Ele provém de uma família de monges da cidade de Otsu, província japonesa de Shiga, lembrando que a constituição de corpos familiares monásticos é relativamente comum no Japão, na medida em que os especialistas religiosos de vertente Verdadeira Escola da Terra Pura não precisam ser celibatários (o próprio Katata é casado). De acordo com o monge, antes de ser ordenado como tal, ele não queria sê-lo, desejando tocar numa banda. Portanto, teria sido uma coerção que o levaria a tornar-se um especialista religioso, o que é particularmente importante na organização familiar nipônica, na qual o indivíduo possui pouca mobilidade em relação ao controle da família (ANDRÉ, 2014b). No entanto, a inclinação musical de Katata é recorrentemente utilizada em suas pregações. Durante o Hatsubon, que deu início ao Obon Matsuri de 2014, que será mais bem explicado adiante, ele tocou e cantou uma música intitulada "Himawari", literalmente "Girassol", que recitava diversas vezes o Nenbutsu. Durante o Bon Odori, num dos intervalos, trajado com camiseta e calça preta comuns, ele e sua banda, denominada "Oteirazão" (aumentativo abrasileirado de otera, isto é, "templo"), que incluía sua esposa e um membro do grupo de jovens do templo, cantaram e tocaram músicas do jrock, como é chamado o rock japonês. Essas e outras atividades parecem gerar certo carisma de Katata entre o público jovem do Honpa Honganji, atribuindo-Ihe capital religioso não apenas devido às suas performances monásticas, mas também em razão de sua aproximação para com os interesses juvenis.

\section{Mortos que Voltam no Além-Mar}

Certas atividades ligadas ao templo, tendo à frente Katata, remetem às estratégias de proselitismo para atrair mais adeptos. Pode-se destacar, entre outras, a realização de grupos de jovens, gincanas e mesmo a venda de feijoada em alguns finais de semana. No entanto, o evento de maior popularidade do Honpa Honganji é o Bon Odori. Em Londrina, o rito é tão popular que ganhou versões laicizadas, destituídas do caráter sagrado que perpassa o ritual mortuário, sendo feitas fora do contexto do Obon Matsuri em diversos lugares e ocasiões, como, por exemplo, durante o Londrina Matsuri, festival nipo-brasileiro realizado anualmente na cidade no Parque de Exposições Ney Braga. De qualquer forma, o Bon Odori realizado no templo é o mais tradicional da região, ainda que apropriando diferentes elementos culturais. 
De maneira geral, de acordo com a observação participante (ANDRÉ, 2014a), é possível dividir o Obon Matsuri realizado pelo templo Honpa Honganji em momentos diferentes que refletem as problemáticas sugeridas do Budismo em solo brasileiro. No dia 16 de agosto de 2014, às 14h00, ocorreu a chamada "Oração para as famílias", dando início ao Hatsubon, marcado pelo primeiro ano após o falecimento de algum familiar (JAPAN-GUIDE, [2007?]). A cerimônia é voltada para a recitação dos nomes dos que morreram no período, já que, como explicou Katata, que ministrou o rito, os espíritos dos mortos voltariam no período. O público era composto por cerca de trinta nikkeis, provavelmente fieis do templo. O rito foi ministrado quase inteiramente em japonês, com poucas partes, geralmente introdutórias, em português. O uso do japonês é constante e não apenas nos momentos do rito, mas também nas conversas entre os fieis antes, durante e depois da celebração. $O$ monge apresentou-se a princípio de terno e gravata, trocando-se, logo no início, para as vestes monásticas. O ritual começou com Katata perguntando os nomes dos parentes falecidos desde agosto de 2013, convidando o público, logo em seguida, a oferecer incenso no altar. Mais à frente, além das três figuras tradicionais dos templos de Verdadeira Escola da Terra Pura (Shinran, o fundador da escola; Rennyo, um dos renovadores da vertente e, ao centro, o Buda Amida), havia uma série de tabuletas denominadas ihai, nas quais são escritos os nomes dos ancestrais, sendo inseridas nos altares domésticos. Além disso, havia pacotes embrulhados contendo incenso que, ao final da cerimônia, seriam entregues àqueles que perderam familiares no último ano. Voltando à sequência ritualística, enquanto fieis queimavam incenso, o monge recitava sutras, o que era intercalado, periodicamente, pelo toque de um sino. Após essa primeira parte, mais propriamente recitativa, Katata fez um comentário de aproximadamente uma hora explicando elementos como a etimologia da palavra Obon, a origem mitológica do festival, os quatro sofrimentos essenciais dos preceitos budistas (viver, envelhecer, adoecer e morrer), a inevitabilidade da morte e, por fim, a necessidade de compreensão do sofrimento. Após os comentários, o monge tocou e cantou "Himawari", como sugerido mais acima, convidando todos a recitar o Nenbutsu, o que ocorreu de forma tímida. Após a música, ele entregou os ihai e os incensos para as famílias, aparentemente encerrando a cerimônia. Em seguida, todos foram para o barracão anexo ao templo para comer alimentos como pastel, frango empanado, sushi e beber chá.

O Hatsubon é um rito mortuário por dois motivos. Em primeiro lugar, ele abre o Obon Matsuri que, como afirmado, marca o período em que os mortos voltariam para o mundo dos vivos. Além disso, a cerimônia é importante no sentido de transformar os falecidos em ancestrais propriamente ditos, na medida em que os ihai são confeccionados pelo monge budista com o intuito de permitir o culto doméstico aos ancestrais. As tabuletas, como 
afirmado, são inseridas no butsudan, não apenas representando a memória do falecido em sentido moderno, mas evocando sua presença como entidade protetora da família, sendo necessário que os viventes realizem oblações na forma, principalmente, de alimentos no sentido de completar a troca simbólica (SANSOM, 1973; ANDRÉ, 2011b). Não é coincidência que Katata recite os nomes dos trespassados: diferentemente da liturgia cristã, em que a recitação desempenha o papel de lugar de memória de seres ausentes, no caso do Budismo de Terra Pura os espíritos seriam de fato invocados. A queima de incensos, em si, remete às oferendas aos ancestrais tornados presentes. A entoação de sutras, marcada periodicamente pelo toque de um sinete, define a entrada num tempo sagrado (ELIADE, 2001) que, diferentemente do tempo profano, é perpassado pela presença dos mortos. Essa duração apenas termina, teoricamente, com o fim do Obon e o exorcismo espiritual caracterizado, em algumas escolas budistas, pelo Tôrô Nagashi. Aliás, a entrada no tempo sagrado parece ser simbolizada, também, pela troca das vestes profanas (civis) pelas vestes monásticas.

Durante a observação do Hatsubon, como afirmado, notou-se a presença de um público, sobretudo, nikkei. São indivíduos de primeira, segunda e terceira geração de japoneses, constituindo representantes de um Budismo étnico, às vezes dominando apenas o idioma japonês, sabendo algumas palavras do português. Esse Budismo, como afirmado, enfrenta certos desafios, tendo em vista os processos de conversão entre os descendentes para outras religiões e o abandono das antigas práticas dos pais e avós. Esses indivíduos eram membros do templo e interessados no rito fúnebre, aparentemente não havendo, com exceção dos autores deste artigo, pessoas da comunidade externa.

De forma geral, o Hatsubon observado segue uma estrutura mais ou menos tradicional, sendo a recitação de sutras (a parte mais propriamente litúrgica) seguida pelos comentários. Talvez a única inovação perceptível tenha sido a performance musical de Katata como forma de atrair a atenção do público. Porém, como sugerido, parece ter havido pouco envolvimento dos ouvintes, tímidos e reservados. A comida após a cerimônia marca o caráter social que envolve a morte domesticada nas religiões e religiosidades japonesas, bem como a materialidade dos mortos que deveriam ter suas necessidades básicas atendidas. Nesse sentido, a comida não seria apenas uma atividade profana seguida ao Hatsubon, mas prática sagrada que faz parte do mesmo, encontrando-se no interior do tempo sagrado. Afinal, sua realização é justificada pelo próprio mito de origem relativo à narrativa de Mokuren.

Nos dias 16 e 17 de agosto à noite, foi realizada a segunda parte do Obon Matsuri, o Bon Odori propriamente dito. Ao centro do pátio, há uma estrutura de madeira montada 
exclusivamente para a cerimônia, sobre a qual indivíduos trajados com roupas festivas japonesas tocam os tambores. O toque segue o ritmo executado ao fundo por músicas gravadas que vão desde canções nipônicas tradicionais, como o "Tankô bushi”, a execuções mais contemporâneas que apropriam elementos do rock, como "Giza giza heart". Lanternas (chôchin) iluminadas por lâmpadas em seu interior decoram quase todo o ambiente, nas quais se encontram escritos em japonês (às vezes em português, mas em menor quantidade) nomes de famílias, estabelecimentos comerciais, kumi e de políticos regionais. Em torno da estrutura de madeira, de forma circular, pessoas dançam ao ritmo do som dos tambores, com passos em grande parte convencionados que parecem basear-se em práticas cotidianas como a pesca e a colheita: desde os membros mais velhos da comunidade nipônica, atinando-se para a presença de grupos de dança organizados como o Hikari, vestidos a caráter, aos indivíduos mais jovens, trajados ou não com vestimentas tradicionais, que eventualmente criam movimentos a partir do repertório preestabelecido com passos, às vezes, que se assemelham àqueles do break. Em determinado momento do rito, passadas cerca de duas horas, são executadas quase exclusivamente as músicas modernas, seguidas de danças mais rápidas realizadas pelos mais jovens. No dia 16 de agosto, durante o intervalo, como sugerido, Katata e sua banda tocaram algumas músicas. Num barracão ao lado do templo, são vendidos vários tipos de comida, de sushi a pastéis. Dentro do templo, que permanece de portas abertas durante o Bon Odori, os incensos dedicados aos ancestrais queimam para quem quiser oferecê-los aos mortos protetores (ANDRÉ, 2014a).

Trata-se da ritualização da narrativa de origem sobre Mokuren e sua mãe falecida. Um dos elementos simbólicos do Bon Odori parece ser a circularidade: os dançarinos circulam a estrutura de madeira continuamente, bem como as músicas (mesmo as modernas) são repetidas num repertório mais ou menos limitado de dez canções. Isso pode remeter a questões importantes, como o eterno retorno do tempo sagrado, na medida em que o rito seria uma forma de reatualizar o mito (ELIADE, 2001): os mortos retornariam todos os anos na mesma época. Além disso, de forma residual, esse traço pode sugerir a circularidade do imaginário budista, marcado pelo princípio do samsara e da transmigração dos espíritos por diferentes círculos espirituais, embora, como afirmado, a religiosidade Mahayana do Budismo japonês tenha modificado essas concepções. Por fim, os movimentos inerentes às danças, voltados para as práticas cotidianas, podem aludir à circularidade que caracteriza o tempo da natureza, matizado pela passagem das estações do ano. É válido lembrar que, no Japão, os elementos sazonais perpassam o imaginário social de diferentes formas. Eles são utilizados, por exemplo, nos haiku, a poesia metricamente estruturada em três versos 
contendo cinco, sete e cinco sílabas, bem como na contemplação do mundo natural por intermédio da observação da floração das cerejeiras (FERGUSON, 2007).

As lanternas penduradas ao longo de todo o pátio do templo remetem a diferentes aspectos do rito. Por um lado, algumas delas são artefatos de invocação dos mortos, lembrando que, no Japão, a escrita dos nomes permitiria evocar a presença dos falecidos e mesmo de certas qualidades, fenômeno denominado kotodama, literalmente "espírito da palavra" (MAEYAMA, 1967). Não é coincidência que os nomes sejam escritos nos ihai e nos pequenos barcos confeccionados quando do Tôrô Nagashi em certas regiões do Japão e do Brasil, demandando pela necessidade de exorcizar aqueles que foram invocados quando do Obon Matsuri. Também não parece casual que todos os indivíduos dancem sob as lanternas, representação, talvez, da possibilidade de elevação espiritual dos falecidos.

A ostentação dos sobrenomes familiares nas lanternas remete, também, ao caráter familista sobre o qual se buscou estruturar a organização da comunidade nikkei. No Brasil, inclusive em Londrina, tentou-se reconstruir os padrões familiares existentes no Japão a partir do sistema de ie, fundamentado no patriarcalismo. A responsabilidade sobre ie consistiria na manutenção da propriedade familiar (principalmente rural) e, também, do culto aos ancestrais (MAEYAMA, 1973). No entanto, as várias características inerentes à sociedade brasileira, como a necessidade de trabalhar e/ou estudar fora, bem como os casamentos interétnicos realizados com os gaijin (expressão pejorativa utilizada por membros da comunidade nikkei para referir-se ao não descendente), criou obstáculos para a consolidação do ie fora de sua sociedade de origem (SATO, 1999; ASARI, 1992; ANDRÉ, 2011b). Mesmo assim, durante o Bon Odori, a inscrição dos nomes familiares nas lanternas parece ser uma forma de resistência do familismo nipônico no Brasil, remetendo, também, ao caráter comunitário que envolve a realização de diferentes atividades, como o próprio rito em foco, recordando que o próprio templo como um todo foi construído nos anos 1950 a partir dessas redes de solidariedade.

Outro elemento que se pode destacar nas lanternas é a presença dos kumi, indicados a partir de sua numeração: "19 kumi”, por exemplo. Trata-se, como afirmado, de uma forma de organização da comunidade nipônica em Londrina que seguia a forma das vilas rurais japonesas, os mura. Mesmo se formando nos primeiros anos da presença nipônica na região, ainda numa conjuntura bairrista que se aproximava das características do ambiente rural, os kumi ainda parecem fazer sentido atualmente em uma Londrina mais urbana como mecanismo de divisão espacial dos nikkei e de organização das atividades, integrando os ie numa arquitetura social de caráter familiar. Desta forma, pode-se dizer que o kumi é uma extensão do ie. Mesmo os políticos nikkeis, inserindo-se numa sociedade civil mais ampla 
que o universo nipo-brasileiro, precisam articular-se estrategicamente aos kumi como forma de constituir capital político ${ }^{23}$ entre os membros da comunidade. Não é casual, nesse sentido, que políticos utilizem o Bon Odori, também, como local de campanha, ostentando seus nomes nas lanternas e em faixas anexas à estrutura central sobre a qual se toca os tambores. Mesmo as empresas de capital nikkei parecem integrar-se nessa rede de solidariedade em torno do kumi.

Mesmo sendo o Bon Odori mais tradicional de Londrina quando comparado às versões leigas promovidas em ocasiões como o Matsuri Dance ${ }^{24}$, são apropriados no rito elementos de festividades católicas e do universo pop nipônico. Não se trata de uma assimilação que somente reproduz aspectos de outros sistemas simbólicos, mas da apropriação que, como ressalta Chartier (2002), constrói diferentes significados sobre o ritual. Isso remete ao caráter dinâmico da Verdadeira Escola da Terra Pura na cidade, representada pelo templo Honpa Honganji, que, por meio dos sujeitos envolvidos com a religião, estabelece uma negociação com diferentes elementos culturais com o objetivo de realizar o proselitismo religioso e, ao mesmo tempo, oferecer condições para a reprodução social e cultural dessa escola budista no local.

Dentre as apropriações, em primeiro lugar, pode-se destacar a utilização de algumas músicas das festas de São João, dançadas em pares, o que pode remeter a um possível sincretismo com as práticas religiosas católicas. Além disso, tocam-se canções do jpop (o pop japonês) e do jrock que, como afirmado, são ligadas a danças com ritmos mais rápidos. Às vezes, a coreografia se assemelha àquela utilizada nas canções "originais": os movimentos base de "Tankô bushi", mais tradicional, são seguidos em "Giza giza heart", embalada pelo rock, porém se apropriando de algumas variações executadas mais rapidamente. Em terceiro lugar, pode-se destacar a banda de Katata executando músicas do jrock. O "monge roqueiro", na ocasião, parece ter sido bem recebido pelos mais jovens (diferentemente de quando tocou "Himawari" no Hatsubon, quando a recepção foi tímida), embora não se possa afirmar categoricamente que todo o público tenha aceitado essa performance artística, que fugia ligeiramente da sequência ritualística do Bon Odori no Honpa Honganji.

A quantidade de pessoas presentes no Bon Odori é incomparavelmente superior àquela dos ritos anteriores, além de serem indivíduos, em sua maioria, com objetivos

23 Assim como o capital religioso, o capital político pressupõe a autoridade que é atribuída por alguém a um indivíduo ou grupo no sentido de permitir que seu discurso e ações possuam efeito de verdade (BOURDIEU, 2000).

24 O Matsuri Dance (literalmente, "Festival de Dança") mantém vários elementos do Bon Odori: a dança circular e o toque dos tambores, mas utiliza amplamente músicas e danças modernas e agitadas. Todavia, ele não constitui um rito religioso, podendo ser realizado fora do tempo sagrado do Obon Matsuri e, também, em locais que não sejam templos budistas. 
diferentes dos fieis que participaram das missas, frequentadores do Honpa Honganji. Enquanto o Hatsubon comportava cerca de trinta pessoas, o Bon Odori possuía aproximadamente cem, muitos dos quais não retornam ao templo em outras ocasiões (ANDRÉ, 2014a). Além disso, trata-se de uma diferença étnica e etária: no Hatsubon, quase todos os presentes eram nikkeis de segunda e terceira geração; no Bon Odori, o público era multiétnico e de faixas etárias variadas. A presença de jovens descendentes e não descendentes foi considerável. Sua participação nas danças se tornou mais intensa após a apresentação da banda "Oteraizão", quando as músicas mais modernas se tornaram mais frequentes. $\mathrm{Na}$ atual conjuntura da sociedade brasileira, as diversas representações sobre o Japão tornaram-se um fenômeno cotidiano, de forma que, como argumenta o historiador norte-americano Jeffrey Lesser (2013), os jovens de classe média passaram a se interessar pelos elementos "exóticos" japoneses, como os alimentos, os mangás e os animes, respectivamente os quadrinhos e as animações nipônicos. Esses jovens que pintam o cabelo de diferentes cores, interessados pelos aspectos exóticos, e os curiosos que foram até o templo para reencontrar amigos e manter os laços de sociabilidade, são um público visado pelo templo.

Nesse sentido, pode-se dizer que o Bon Odori é o principal meio utilizado pelo templo Honpa Honganji para chamar a atenção de públicos diferenciados, considerando as particularidades étnicas do Budismo de Verdadeira Escola da Terra Pura. No entanto, segundo Katata, vários dos indivíduos que participam do rito parecem não retornar ao templo em outras ocasiões, não constituindo, portanto, fieis frequentadores da religião (ANDRÉ, 2014b). Além disso, embora não tenham sido feitas entrevistas especificamente voltadas para a forma como os participantes do Bon Odori se apropriam do mesmo, aparentemente eles não atentam para o caráter mortuário que perpassa a cerimônia, inserida na conjuntura do Obon Matsuri. Nesse sentido, o festival pode ser visto como forma de entretenimento que oferece um serviço pontual, não implicando, necessariamente, numa adesão aos preceitos e às práticas da Verdadeira Escola da Terra Pura.

No dia 17 à tarde foi realizado um rito denominado pelo monge em português "Cerimônia para Todos". Mesmo assim, o público era composto, sobretudo, por nikkeis, tal como no Hatsubon. O traje de Katata era diferente do dia anterior, sendo uma roupa amarela com leques, aparentemente menos cerimoniosa. A princípio, foram cantados hinos em japonês da Verdadeira Escola da Terra Pura com todos os presentes em pé. A seguir, houve palavras do presidente do templo, recordando que, na escola budista em questão, há um monge responsável pelas práticas religiosas e um presidente leigo (uma espécie de presbítero no caso das igrejas presbiterianas) que gerencia o local. A propósito, durante o 
Obon Matsuri, foram pendurados nas paredes do templo quadros dos monges (à esquerda, trajando vestes monásticas) e dos nove presidentes até então (à direita, com roupas civis). Voltando à sequência ritualística, houve o oferecimento de flores ao altar diante de Shinran, Amida e Rennyo. Katata realizou cantos ritualísticos diante do altar e contou, novamente, o mito de Mokuren. Os membros mais jovens ofereceram incenso fazendo reverência ao altar, utilizando golas com o símbolo (mon) do Honpa Honganji. Após o ato, o monge saiu de cena por uma porta atrás do altar, invisível ao público, retornando posteriormente e recitando sutras. Terminada a parte litúrgica, Katata passou para o sermão, falando sobre as semelhanças do Obon Matsuri com o Finados no Ocidente. Além disso, sugeriu as possíveis heranças das músicas japonesas em relação às canções indianas, utilizando de sua guitarra para isso, concluindo, metaforicamente, que a harmonização de sons e tradições seria semelhante às ideias das pessoas que, mesmo contraditórias, poderiam tornar-se harmônicas uma vez que os indivíduos trabalhem juntos (ANDRÉ, 2014a).

Apesar das semelhanças entre a "Cerimônia para Todos" e o Hatsubon, pensando na estrutura voltada para a recitação de sutras e os comentários, percebe-se que, no caso do segundo, tratava-se de um rito mais voltado para os membros do templo, especialmente as famílias enlutadas desde o último Obon Matsuri. Embora não fosse um ritual secreto, o Hatsubon seria mais voltado para os iniciados e os agregados à comunidade budista. A Cerimônia para Todos, como o próprio nome indica, seria direcionada para todos os possíveis interessados, disso derivando a ênfase dada aos mais jovens, que teriam o papel de oferecer condições para a reprodução social e cultural do templo e da religião como um todo. Isso se insere na conjuntura de desafios enfrentados pela Verdadeira Escola da Terra Pura em Londrina, fundamentada num Budismo étnico que precisa criar mecanismos para perpetuar-se ao longo do tempo. A ênfase de Katata, durante o comentário, nos sons que se misturam formando harmonias pode remeter a essa necessidade de acomodação cultural do Budismo em território brasileiro. De forma geral, o rito pareceu menos cerimonioso que o Hatsubon em vários sentidos, como nas vestes monásticas, nos assuntos discutidos e na participação do público não adepto ao templo. Mesmo assim, a Cerimônia para Todos foi ministrada quase inteiramente em língua japonesa, com poucas intervenções em português, havendo um público ainda muito parecido, em termos de perfil e quantidade, àquele presente no Hatsubon. Aparentemente, os não adeptos que participaram do Bon Odori nos dois dias à noite não apareceram nas missas.

O Hatsubon, o Bon Odori e a Cerimônia para Todos fazem parte de um todo que se insere no Obon Matsuri, recordando, como sugere Arnold Van Gennep (2011), que os ritos devem ser compreendidos na totalidade de sua narrativa, articulando-se as partes num 
conjunto mais ou menos coerente. Percebe-se, ao longo da conjuntura, certa "volatilidade" do espaço sagrado: no Hatsubon, o templo é para os iniciados; no Bon Odori e na Cerimônia para Todos, para o público externo. Nesse sentido, pode-se afirmar que o lugar sagrado não seria estanque, mas, como afirmado, algo volátil que depende dos momentos cerimoniais. Pode-se, igualmente, inverter o raciocínio ao pensar que o profano adentra no sagrado em determinados momentos, não havendo, portanto, uma fronteira invariável entre ambas as dimensões.

A partir da observação participante, percebe-se que o Bon Odori possui um diferencial quanto comparado ao Hatsubon (e mesmo à Cerimônia para Todos), na medida em que, utilizando ostensivamente de apropriações de elementos das festividades católicas e do universo pop, consegue atrair um público variado em termos de perfil e quantidade que, entretanto, não adere necessariamente ao templo e aparenta não atinar para o caráter mortuário que perpassa o Bon Odori. Trata-se, portanto, de uma das estratégias de proselitismo utilizadas pelo Honpa Honganji, que necessita consolidar-se como campo religioso diante dos desafios do Budismo étnico ou de imigração.

\section{Considerações Finais}

Como visto ao longo do artigo, o Bon Odori é um ritual que, inserido no Obon Matsuri, possui caráter mortuário voltado para a elevação dos espíritos no interior dos diferentes círculos de morte e renascimento. No Japão, por intermédio das apropriações que o Budismo Mahayana realizou das religiosidades chinesa e japonesa, ele se tornou uma cerimônia marcada pelo retorno dos ancestrais do outro mundo, a Terra Pura, devendo ser reverenciados em sua materialidade por meio de danças, músicas e alimentos. Isso remete ao caráter doméstico da morte no Japão, que seria próxima aos viventes na medida em que o culto mortuário está presente nas casas e nos templos, demandando por práticas coletivas e cotidianas, como no caso do butsudan.

No Brasil, essas práticas mortuárias foram reconstruídas considerando as características particulares da sociedade receptora. Em cidades como Londrina, a religião em nível institucional consolidou-se tardiamente, a partir da segunda metade do século XX, com a construção de templos tendo à frente monges especializados. No entanto, devido ao caráter étnico do Budismo de imigração, o Templo Nishi Honganji enfrenta desafios, porquanto os membros mais velhos estejam progressivamente morrendo, demandando por estratégias de proselitismo para garantir as condições de reprodução social da religião em território londrinense. O Bon Odori, nesse sentido, é uma das práticas mais populares do 
templo, apropriando-se de diferentes elementos culturais, sem, no entanto, conseguir que os frequentadores se tornem adeptos da Verdadeira Escola da Terra Pura.

\section{Referências}

ALBERTI, Verena. Fontes orais: histórias dentro da história. In: PINSKY, Carla Bassanezi (org.). Fontes históricas. 3. ed. São Paulo: Contexto, 2011. p. 155-202.

ALBUQUERQUE, Leila Marrach Basto de. Seicho-no-ie do Brasil: agradecimento, obediência e salvação. São Paulo: Annablume, 1999.

ANDRÉ, Richard Gonçalves. Imigrantes curandeiros: facetas da religiosidade nipônica no Brasil (1908-1950). In: HAHN, Fábio André; MEZZOMO, Frank Antonio (org.). Nas malhas do poder. história, cultura e espaço social. Campo Mourão: Editora FECILCAM, 2011a. p. 77-100.

ANDRÉ, Richard Gonçalves. Lacunas historiográficas: uma perspectiva sobre as religiões japonesas nos eventos da ABHR e nas Jornadas sobre Alternativas Religiosas na América Latina. Revista Nures, São Paulo, n. 10, set./dez. 2008.

ANDRÉ, Richard Gonçalves. Religião e silêncio: representações e práticas mortuárias entre nikkeis em Assaí por meio da cultura material (1929-1950). 2011. Tese (Doutorado em História) - Universidade Estadual Paulista, Assis, 2011b.

ARIÈS, Phillipe. O homem diante da morte. 2. ed. Rio de Janeiro: Francisco Alves, 1989.

ASARI, Alice Yatiyo. “... E eu só queria voltar ao Japão”: colonos japoneses em Assai. 1992. Tese (Doutorado em Geografia) - Universidade de São Paulo, São Paulo, 1992.

BENEDICT, Ruth. O crisântemo e a espada: padrões da cultura japonesa. São Paulo: Perspectiva, 1972.

BOURDIEU, Pierre. A economia das trocas simbólicas. 6. ed. São Paulo: Perspectiva, 2005.

BOURDIEU, Pierre. O poder simbólico. 3. ed. Rio de Janeiro: Bertrand Brasil, 2000.

BUDISMO da Terra Pura: um guia. São Paulo: Comunidade Budista Sul Americana da Escola Jodo Shinshu Honpa Hongwanji, 2013.

CHARTIER, Roger. À beira da falésia: a História entre certezas e inquietudes. Porto Alegre: Editora da UFRGS, 2002.

COHEN, Nissim. Ensinamentos do Buda: uma antologia do Cânone Páli. São Paulo: Devir Livraria, 2008.

DYKSTRA, Yoshiko K. Tales of the compassionate Kannon: the Hasedera Kannon Genki. Monumenta Nipponica, Tokyo, v. 31, n. 2, 1976.

ELIADE, Mircea. História das crenças e das ideias religiosas Il: de Gautama Buda ao triunfo do Cristianismo. Rio de Janeiro: Zahar, 2011. 
ELIADE, Mircea. O sagrado e o profano: a essência das religiões. São Paulo: Martins Fontes, 2001.

ENNES, Marcelo Alario. A construção de uma identidade inacabada: nipo-brasileiros no interior do Estado de São Paulo. São Paulo: Editora Unesp, 2001.

EPSTEIN, Ron. Clearing up some misconceptions about Buddhism. Vajra Bodhi Sea: a Monthly Journal of Orthodox Buddhism, Talmage, p. 41-43, Feb. 1999.

FERGUSON, Will. De carona com Buda: o Japão de cabo a cabo. São Paulo: Companhia das Letras, 2007.

FUJII, Masao. Maintenance and change in Japanese traditional funerals and death-related behavior. Japanese Journal of Religious Studies, Tokyo, v. 10, n. 1, p. 39-64, 1983.

GEERTZ, Clifford. A interpretação das culturas. Rio de Janeiro: LTC, 2008.

GONÇALVES, Ricardo Mário. A religião no Japão na época da emigração para o Brasil e suas repercussões em nosso país. In: O JAPONÊS em São Paulo e no Brasil. São Paulo: Centro de Estudos Nipo-Brasileiros, 1971. p. 58-73.

GONÇALVES, Ricardo Mário. O Budismo: história e doutrina. In: GONÇALVES, Ricardo Mário (org.). Textos budistas e zen-budistas. São Paulo: Editora Cultrix, 1993a. p. 11-33.

GONÇALVES, Ricardo Mário. Textos budistas e zen-budistas. São Paulo: Editora Cultrix, 1993b.

HANDA, Tomoo. O imigrante japonês: história de sua vida no Brasil. São Paulo: T. A. Queiroz: Centro de Estudos Nipo-Brasileiros, 1987.

JAPAN-GUIDE. Obon festival. In: JAPAN-GUIDE. [S. I.], [2007?]. Disponível em: http://www.japan-guide.com/forum/quereadisplay.html?0+39232. Acesso em: 29 nov. 2014.

LESSER, Jeffrey. A negociação da identidade nacional: imigrantes, minorias e a luta pela etnicidade no Brasil. São Paulo: Editora Unesp 2001.

LESSER, Jeffrey. Um Brasil melhor. História, Ciências, Saúde: Manguinhos, Rio de Janeiro, v. 21, 2013.

MAESIMA, Cacilda. Japoneses, multietnicidade e conflito na fronteira: Londrina, 1930/1958. 2012. Tese (Doutorado em História) - Universidade Federal Fluminense, Rio de Janeiro, 2012.

MAEYAMA, Takashi. O antepassado, o imperador e o imigrante: religião e identificação de grupo dos japoneses no Brasil rural (1908-1950). In: SAITO, Hiroshi; MAEYAMA, Takashi (org.). Assimilação e integração dos japoneses no Brasil. São Paulo: Editora da Universidade de São Paulo, 1973a. p. 414-447.

MAEYAMA, Takashi. O imigrante e a religião: estudo de uma seita religiosa japonesa em São Paulo. 1967. Dissertação (Mestrado em Antropologia) - Universidade de São Paulo, São Paulo, 1967. 
MAEYAMA, Takashi. Religião, parentesco e as classes médias dos japoneses no Brasil urbano. In: SAITO, Hiroshi; MAEYAMA, Takashi (org.). Assimilação e integração dos japoneses no Brasil. São Paulo: Editora da Universidade de São Paulo, 1973b. p. 240-272.

MARTINS, José de Souza. A morte e o morto: tempo e espaço nos ritos fúnebres da roça. In: MARTINS, José de Souza (org.). A morte e os mortos na sociedade brasileira. São Paulo: Editora Hucitec, 1983. p. 258-269.

MATSUE, Regina Yoshie. O Budismo da Terra Pura em Brasília. In: USARSKI, Frank (org.). O Budismo no Brasil. São Paulo: Editora Lorosae, 2002. p. 193-219.

MUTSURÔ, Kai. Shin kokugo jiten. Tokyo: Mitsumura Tosho, 2007.

NAKAMAKI, Hirotika. A Honmon Butsuryu-shu no Brasil. São Paulo: Religião Budista Honmon Butsuryu-shu do Brasil, 1993.

ORTIZ, Renato. A morte e sua sombra. In: MARTINS, José de Souza (org.). A morte e os mortos na sociedade brasileira. São Paulo: Editora Hucitec, 1983. p. 188-200.

REIS, João José. A morte é uma festa: ritos fúnebres e revolta popular no Brasil do século XIX. São Paulo: Companhia das Letras, 1991.

SANSOM, George Bailey. Japan: a short cultural history. Tokyo: Charles E. Tuttle, 1973.

SATO, Lilian Hissami. A imigração japonesa para o Norte do Paraná: Assaí, 1930-1980. 1999. Monografia (Especialização em História) - Universidade Estadual de Londrina, Londrina, 1999.

SETO, Claudio; UYEDA, Maria Helena. Ayumi: caminhos percorridos. Curitiba: Imprensa Oficial do Paraná, 2002.

SOARES, Marco Antonio Neves. Fontes para a investigação das identidades e religiosidades judaicas longe do judaísmo instituído: o caso de Rolândia. Revista Brasileira de História das Religiões, Maringá, n. 4, maio 2009.

STREAMS of Light: Shin Buddhism in America. Direção: Kentaro Sugao. São Paulo: Ebisu Filmes, 2013. 1 DVD (62 min), son., color.

TAKEUCHI, Márcia Yumi. O perigo amarelo em tempos de guerra (1939-1945). São Paulo: Imprensa Oficial do Estado, 2001.

TOMAZI, Nelson Dacio. "Norte do Paraná": histórias e fantasmagorias. Curitiba: Aos Quatro Ventos, 2000.

UNNO, Mark. Shingon refractions: Myôe and the Mantra of Light. Somerville: Wisdom Publications, 2004.

USARSKI, Frank. Declínio do budismo "amarelo" no Brasil. Tempo Social, São Paulo, v. 20, n. 2, p. 133-153, 2008.

USARSKI, Frank. O Budismo no Brasil: um resumo sistemático. In: USARSKI, Frank (org.). O Budismo no Brasil. São Paulo: Editora Lorosae, 2002. p. 9-33. 
VALLADARES, Clarival do Prado. Arte e sociedade nos cemitérios brasileiros. Rio de Janeiro: Conselho Federal de Cultura, 1972. v. 1.

VAN GENNEP, Arnold. Os ritos de passagem. 3. ed. Petrópolis: Vozes, 2011.

WEBER, Max. The religion of India: the sociology of Hinduism and Buddhism. Glencoe: The Free Press, 1958.

WIJAYARATNA, Mohan. Funerary rites in Japanese and other Asian Buddhist societies. Japan Review, Kyoto, n. 8, p. 105-125, 1997.

YOKOYAMA, Lia Cazumi. A conversão ao Catolicismo. 1998. Dissertação (Mestrado em História) - Universidade de São Paulo, São Paulo, 1998.

\section{Fontes Primárias}

AMIDAKYO: o sutra do Buda Amida. Kyoto: Jodo Shinshu Studies and Research Center, 2004.

ANDRÉ, Richard Gonçalves. Caderno de campo. 2014a. Acervo pessoal.

ANDRÉ, Richard Gonçalves. Entrevista com Elminha Kazumi Tokairin. 2017. Acervo pessoal.

ANDRÉ, Richard Gonçalves. Entrevista com Estela Okabayaski Fuzii. 2015. Acervo pessoal.

ANDRÉ, Richard Gonçalves. Entrevista com Genyû Katata. 2014b. Acervo pessoal.

COMISSÃO DE RECENSEAMENTO DA COLÔNIA JAPONESA (ブラジル日系人実態調査委員会, Burajiru nikkeijin jitai chousa iinkai). O imigrante japonês no Brasil (ブラジルの日本移民, Burajiru no nihon imin). Tokyo: University of Tokyo Press, 1969. v. 2.

DELEGADO de Polícia de Assaí (Almir de Medeiros Crespo) ao Chefe de Polícia do Estado (A. P. Lira) em 26 abr. 1948. In: Departamento de Ordem Política e Social do Paraná. Sociedade terrorista japonesa, n. 2205, cx. 241. DEOPS-PR, 1948-1951.

Recebido em 09/12/2017

Aprovado em 30/07/2018 